\title{
HPV E6/E7 mRNA In Situ Hybridization in Endocervical Adenocarcinoma: Implications for Prognosis and Diagnosis
}

\section{Rong-Zhen Luo}

Sun Yat-Sen University Cancer Prevention and Treatment Center: Sun Yat-sen University Cancer Center Shu-Lin Chen

Sun Yat-Sen University Cancer Prevention and Treatment Center: Sun Yat-sen University Cancer Center Mei Li

Sun Yat-Sen University Cancer Prevention and Treatment Center: Sun Yat-sen University Cancer Center Yue Li

Sun Yat-Sen University Cancer Prevention and Treatment Center: Sun Yat-sen University Cancer Center

\section{Xia Yang}

Sun Yat-Sen University Cancer Prevention and Treatment Center: Sun Yat-sen University Cancer Center Li-Li Liu ( $D$ liulil@sysucc.org.cn )

Sun Yat-sen University Cancer Center https://orcid.org/0000-0002-4347-2038

\section{Research Article}

Keywords: Endocervical adenocarcinoma, Prognosis, HPV E6/E7 mRNA in situ hybridization, Lymphovascular invasion, Lymph node involvement.

Posted Date: July 14th, 2021

DOl: https://doi.org/10.21203/rs.3.rs-682463/v1

License: (9) (1) This work is licensed under a Creative Commons Attribution 4.0 International License. Read Full License

Version of Record: A version of this preprint was published at Cancer Cell International on December 1st, 2021. See the published version at https://doi.org/10.1186/s12935-021-02349-1. 


\section{Abstract}

Background: Human papillomavirus (HPV) E6/E7 mRNA in situ hybridization (HPV E6/E7 RNAscope) appears to be a sensitive and specific technique in detecting transcriptionally active HPV. We aimed to examine the diagnostic utility of this technique in endocervical adenocarcinoma (ECA), to explore the prognostic factors for ECA patients and develop a clinically useful nomogram based on clinicopathological parameters to predict it.

Methods: We retrospectively analyzed 200 patients with ECA who had undergone surgery at Sun Yat-sen University Cancer Center from 2010 and 2014. The diagnostic performance of HPV E6/E7 RNAscope were evaluated by receiver operating characteristic (ROC) curve. A prognostic nomogram model including HPV E6/E7 RNAscope was generated based on multivariate Cox regression analysis, then we compared the predictive accuracy of the prognostic model with FIGO staging and treatment using concordance index (C-index), time-dependent ROC (tdROC), and decision curve analysis (DCA).

Results: The sensitivity and specificity of HPV E6/E7 RNAscope for distinguishing HPV-associated adenocarcinoma (HPVA) from non-HPV-associated adenocarcinoma (NHPVA) in the whole cohort were $75.8 \%$ and $80 \%$, respectively. According the univariate analysis and multivariate logistic regression analysis, age, lymphovascular invasion (LVI), lymph node involvement (LNI), and HPV E6/E7 RNAscope were valuable predictive factors for OS. These parameters were incorporated into the nomogram model (nomogram A) compared with FIGO stage and treatment. The C-index of nomogram A for predicting OS was 0.825 , which was significantly higher than FIGO stage (C-index $=0.653, p=0.002)$ and treatment (Cindex $=0.578, p<0.001)$.

Conclusions: HPV E6/E7 RNAscope is highly specific for ECA, and the 4-variable nomogram showed more accurate prognostic outcomes in patients with ECA.

\section{Introduction}

Endocervical adenocarcinoma (ECA) accounts for $15-20 \%$ of all cervical carcinomas. Studies have shown that ECA is increasingly reported in young women[1], with a projected 5-year overall survival (OS) rate of only $20.3 \%$ (95\% confidence interval [CI]: $14.2-27.1 \%$ ) compared to the squamous type $(31.3 \%$, 95\%Cl: 29.2-33.3\%)[2]. The International Federation of Gynecology and Obstetrics (FIGO) staging system is the gold standard for predicting outcomes in patients with ECA, and the mainstay treatment of advanced ECA is concurrent chemoradiotherapy. However, ECA patients with the same FIGO stage can have marked heterogeneities in their outcomes [3, 4]. The new FIGO 2018 amendments put forward by the gynecological oncology committee agree that staging is an ongoing process informed by data on prognosis and survival, and therefore, treatment should be individualized and not merely based on staging given the variability of the resource across regions. FIGO 2018 also recommends any imaging modality and/or pathological findings like lymphovascular invasion (LVI) for allocating staging[3]. 
A new classification-the International Endocervical Adenocarcinoma Criteria and Classification (IECC) has replaced the 2014 WHO classification and categorizes ECA based on the morphological features linked to the etiology (i.e., HPV infection), thus grouping them into HPV-associated (HPVA) and non-HPVA (NHPVA) types[4, 5]. Comparing HPVA with NHPVA types reveals essential differences in tumor biology and patient survival, with NHPVA-type tumors significantly associated with worse outcomes[6, 7]. It is apparent that a classification based on the pathogenesis and other clinicopathological factors may be more clinically useful and reproducible than the current FIGO scheme. The other shortcoming of FIGO is that it doesn't stratify patients based on histology and HPV status. Hence, novel prognostic determinants to complement the FIGO staging system is needed. The validity of this new classification is supported by HPV status but with limited clinical data[8, 9].

In the present studies, the following tests were used to detect HPV infection: HPV DNA, genotype, RNAscope, and immunochemistry (IHC) against p16 protein. Plasma HPV DNA levels can be determined using PCR and is a potential marker for cervical cancer[10]. The other 3 assays can be conducted on formalin-fixed, paraffin-embedded (FFPE) samples. Immunostaining for p16 is a cost-effective and highly sensitive marker but with a low specificity[11]. PCR for HPV genotyping is the gold-standard assay to diagnose active HPV infection[12]. Chromogenic in situ hybridization against RNA can identify HPV in situ via microscopic observation[13]. The technique is expensive but can be used on FFPE samples[14]. In situ detection of HPV E6/E7 mRNA using the RNAscope also appears to be a sensitive and a specific method; hence, we aimed to investigate the potential prognostic utility of this technique in ECAs.

Numerous controversies surround the FIGO staging system, wherefore ECAs are morphologically stratified into $A, B$, and $C$ subgroups using the Silva based on their LVI or lymph node involvement (LNI) status[15]. Tumors characterized by well-demarcated glands with rounded contours are designated as pattern A; tumors with early or limited, localized destructive invasion or inflamed stroma adjacent to an intact gland are designated pattern $B$, while tumors with more aggressive features, including diffusely infiltrative glands, usually associated with extensive, diffuse desmoplastic response are designated pattern C. Therefore, clinicians could provide precision treatment to patients with pattern C tumors. However, stratifying patients based on a single biomarker, such as LVI or LNI alone, can lead to misclassification of tumors and poor patients' prognostication, hence the two parameters should be combined[16]. There is currently no such available nomogram model for patients with ECA that combines HPV, LVI, and LNI status, And other survival prediction models that follow the FIGO staging system have been insufficient.

In the present study, we aim to validate the utility of the novel RNA scope method for detecting HPV RNA in tissue samples for proper initial risk stratification of patients. We also built a nomogram that will compliment FIGO staging for prognostic classification of EAC. We hope the link between these two modalities will bring new insights into the clinical care of EAC patients.

\section{Patients \& Methods}

\section{Sampling}


The present retrospective study included 200 patients with pathologically diagnosed ECA who had been treated at the Sun Yat-sen University Cancer Center from January 2010 to December 2014. We enrolled patients with confirmed pathological diagnoses of ECA with available complete clinical data and test results. We excluded patients with systemic metastasis or with synchronous primaries and any patient with a prior cancer history. The last follow-up period was June 2020. The histological diagnoses were based on our proposal for a new ECA classification: the IECC 2017[9], and patients were grouped into HPVA and NHPVA ECA based on HE staining and microscopic morphology.

\section{Immunohistochemistry (IHC)}

A tissue microarray consisting of the ECA and adjacent non-tumorous tissue was constructed using a tissue array instrument (Minicoreexcilone; Minicore, UK). For each patient, hematoxylin and eosin (H\&E) stained slides were examined, and at least two areas from different regions were marked for sampling. A $1.0 \mathrm{~mm}$ diameter tissue core was punched from the marked fields and re-embedded. FFPE ECA sections were dewaxed in xylene and graded alcohols, hydrated, and washed in PBS. After pretreatment in a microwave oven, endogenous peroxidase was blocked using $3 \%$ hydrogen peroxide in methanol for 20 minutes. This was followed by avidin-biotin blocking using a kit (DAKO, Germany). The slides were then incubated with antibodies for p16 (Roche, Germany), MLH1 (Roche [M1], Germany), PMS2 (Dako [EP51], Germany), MSH2 (ZA0622, Zhongshan, China), MSH6 (Roche [SP93], Germany), and Ki-67 (ZA0502, Zhongshan, China) overnight at $4^{\circ} \mathrm{C}$, washed in PBS, and incubated with biotinylated goat antirabbit/mouse antibodies (DAKO, Germany). The slides were developed using diaminobenzidine (DAB) and counterstained with hematoxylin. Two independent, experienced pathologists evaluated the staining; and p16 was interpreted as positive if diffuse, block-like staining was found in all cores. No staining or patchy staining was interpreted as unfavorable. MSH2/MSH6/PMS2/MLH1 was interpreted as positive if $\geq 1 \%$ of the tumor cell nuclei were positive. Representative images were show in Fig. S1.

\section{HPV DNA}

DNA load of High-risk-HPV (HR-HPV) in plasma sample was evaluated by Digene second generation hybrid capture ( $\mathrm{HC} 2)$ DNA test and in vitro acid hybridization assay with signal amplification using microplate chemiluminescence for HR-HPV DNA detection. A commercial kit detecting high risk was used. The alkaline solution was used to denature the double-stranded DNA, and the liberated single-strand DNA was combined with the RNA probe mix. RNA-DNA hybrids were then transferred to a capture microplate coated with goat polyclonal for immobilization. Subsequently, alkaline phosphatase-conjugated antibodies were added to the RNA-DNA hybrids. After washing, the chemiluminescent substrate was added for signal amplification. Results were analyzed by DIGENE DML 2000 Software. DNA load was expressed by the unit of Relative Light Units/Cutoff Value (RLU/CO), representing the ratio of the light emission of the sample to the average of three positive control samples. HR-HPV DNA load of $1.0(\mathrm{pg} / \mathrm{ml})$ or more was defined as HR-HPV DNA positive.

\section{HPV Genotype}


Tissues were scraped by coverslip as per the labeled region on the H\&E slide and transferred into a clean $1.5 \mathrm{ml}$ centrifuge tube. DNA was extracted using a QIAGEN DNA FFPE Kit (Qiagen, Dusseldorf, Germany) according to the manufacturer's instructions and was quantified with a Nano-Drop2000 (NanoDrop Technologies, Wilmington, DE, USA). HPV was detected by the Human papillomavirus Genotyping Test Kit (Anhui Dajian, Guangzhou, China) using the BioRad CFX96 real-time quantitative PCR instrument. The Roche Cobas 4800 system (Roche, Pleasanton, CA) was used to detect HPV and evaluate the presence of the following 14 types of HPV DNA: 16, 18, 31, 33, 35, 39, 45, 51, 52, 56, 58, 59, 66, and 68.

\section{HPV E6/E7 mRNA in situ hybridization}

The stained slides of each specimen were examined using the RNAscope scoring system, as described in previous studies $[17,18]$. High-risk HPV subtypes were evaluated on all ECAs in the tissue microarray that had sufficient tissue to allow scoring $(n=200)$. HPV fluorescent in situ hybridization (FISH) was performed using a chromogen and the RNAscope system (Advanced Cell Diagnostics; catalog No. 312598). The RNAscope probe "HPV HR18" contains probes that target E6 and E7 mRNA in the following high-risk subtypes: HPV16, 18, 26, 31, 33, 35, 39, 45, 51, 52, 53, 56, 58, 59, 66, 68, 73, and 82. RNAscope results were classified into five degrees based on the following scoring guidelines: score 0 , no staining or less than one dot in every ten cells (visible at 40x magnification); score 1,1-3 dots per cell (visible at 2040x magnification); score 2, 4-10 dots per cell, with very few dot clusters (visible at 20-40x magnification); score $3,>10$ dots per cell, with $<10 \%$ of positive cells having dot clusters (visible at $20 x$ magnification); score $4,>10$ dots per cell with $>10 \%$ of positive cells having dot clusters (visible at $20 x$ magnification). Cases with RNAscope score $\geq 1$ were identified as positive.

\section{Data collection}

Among the patients enrolled, the following variables were recorded: age, the modality of treatment (Surgery with or without chemotherapy/radiotherapy), HPV DNA, HPV subtype, HPV E6/E7 RNAscope, histological type, tumor size, differentiation, LVI, invasion level of the uterine cervix, LNI, parametrium invasion, surgical margin, MMR status, p16, Ki-67, and FIGO stage.

\section{Statistical Analysis}

Statistical investigations were conducted using SPSS 19.0 (IBM Corp., Armonk, NY, USA) and R 3.4.0 (http://www. R-project.org/). Continuous data were expressed as means \pm standard deviations and were analyzed using Student's t-test or Mann-Whitney U test, as appropriate based on the results of the Kolmogorov-Smirnov test. Categorical variables were presented using numbers (percentages) and were analyzed with Fisher's exact test. Survival analysis was conducted utilizing the Kaplan-Meier curves. Univariate and multivariate Cox proportional hazard regression were used to explore the risk factor for OS. The best cutoff values were determined using X-tile[19]. The best cutoff values were determined using Xtile with the following results: age, 37 years; RNAscope, 3.3 (Fig. S2A); tumor size, $4.5 \mathrm{~cm}$, and Ki-67 (12.5\%). Receiver operating characteristic curves (ROC) were generated to compare the diagnostic performance of different detection method for ECA patients. The model's predictive efficiency and 
discriminative capability were defined by a concordance index (C-index) and a calibration curve. A twosided $p$-value $<0.05$ was considered statistically significant.

\section{Results}

\section{Patients' characteristics and survival}

We enrolled 200 patients with ECA for analysis, of which 185 were HPVA and 15 NHPVA (Table 1). Across both groups, the median follow-up period was 68 months (range: 1.5-125.1 months). The 1,3, and 5-year OS rates were $99.5 \%, 90.5 \%$, and $85.0 \%$, respectively. 
Table 1

Patient demographics and clinical charateristics.

Characteristic

\begin{tabular}{|c|c|c|c|c|}
\hline & No. (\%) & No. (\%) & №. (\%) & $\mathrm{P}^{\mathrm{a}}$ \\
\hline Age & & & & 0.014 \\
\hline$\leq 37$ & $34(17.0 \%)$ & $28(82.4 \%)$ & $6(17.6 \%)$ & \\
\hline$>37$ & $166(83.0 \%)$ & 157 (94.6\%) & $9(5.4 \%)$ & \\
\hline HPV DNA & & & & $<0.001$ \\
\hline Negative $(0-1 \mathrm{pg} / \mathrm{ml})$ & $34(17.0 \%)$ & $26(76.5 \%)$ & $8(23.5 \%)$ & \\
\hline Positive ( $\geq 1 \mathrm{pg} / \mathrm{ml}$ ) & $110(55.0 \%)$ & $108(98.2 \%)$ & $2(1.8 \%)$ & \\
\hline Not avaiable & $56(28.0 \%)$ & $51(51.8 \%)$ & $5(4.2 \%)$ & \\
\hline HPV genotype & & & & 0.273 \\
\hline HPV 16 & 49 (24.5\%) & 47 (95.9\%) & $2(4.1 \%)$ & \\
\hline HPV 18 & $60(30.0 \%)$ & $57(95.5 \%)$ & $3(5.0 \%)$ & \\
\hline Other & $11(5.5 \%)$ & $11(100.0 \%)$ & $0(0.0 \%)$ & \\
\hline Negative & $72(36.0 \%)$ & $63(87.5 \%)$ & $9(12.5 \%)$ & \\
\hline Not avaiable & $8(4 \%)$ & 7 (87.5\%) & $1(12.5 \%)$ & \\
\hline HPV RNAscope & & & & 0.003 \\
\hline$\leq 3.3$ & $99(49.5 \%)$ & $86(46.5 \%)$ & $13(13.1 \%)$ & \\
\hline$>3.3$ & $101(50.5 \%)$ & 99 (98.0\%) & $2(2.0 \%)$ & \\
\hline Tumor size (cm) & & & & 0.004 \\
\hline$\leq 4.5$ & $178(89.0 \%)$ & $168(94.4 \%)$ & $10(5.6 \%)$ & \\
\hline$>4.5$ & $22(11.0 \%)$ & $17(77.3 \%)$ & $5(22.7 \%)$ & \\
\hline FIGO stage & & & & $<0.001$ \\
\hline I & $141(70.5 \%)$ & 137 (97.2\%) & $4(2.8 \%)$ & \\
\hline ॥ & $51(25.5 \%)$ & $43(84.3 \%)$ & $8(15.7 \%)$ & \\
\hline III & $5(2.5 \%)$ & $4(80.0 \%)$ & $1(20.0 \%)$ & \\
\hline
\end{tabular}

${ }^{a}$ Chi-square test. HPVA, HPV-associated adenocarcinoma; NHPVA, nonHPV-associated adenocarcinoma; IHC, immunohistochemistry; LVI, lymph vascular invasion; dMMR, delete mismatch repair; pMMR, proficient mismatch repair. 


\begin{tabular}{|c|c|c|c|c|}
\hline Characteristic & Total $(n=200)$ & HPVA $(n=186)$ & NHPVA $(n=16)$ & \\
\hline IV & $3(1.5 \%)$ & $1(33.3 \%)$ & $2(66.7 \%)$ & \\
\hline Differentiation & & & & 0.537 \\
\hline Good & $10(5.0 \%)$ & $7(70.0 \%)$ & $3(30.0 \%)$ & \\
\hline Moderate & $106(53.0 \%)$ & $96(90.6 \%)$ & $10(9.4 \%)$ & \\
\hline Poor & $84(42.0 \%)$ & $82(97.6 \%)$ & $2(2.4 \%)$ & \\
\hline LVI & & & & 0.141 \\
\hline None $(0)$ & $138(69.0 \%)$ & $130(94.2 \%)$ & $8(5.8 \%)$ & \\
\hline Focal (1-4) & $37(18.5 \%)$ & $31(83.8 \%)$ & $6(16.2 \%)$ & \\
\hline Moderate (5-9) & $15(7.5 \%)$ & $14(93.3 \%)$ & $1(6.7 \%)$ & \\
\hline Extensive $(\geq 10)$ & $10(66.7 \%)$ & $10(100.0 \%)$ & $0(0.0 \%)$ & \\
\hline Invasion level of uterine cervix & & & & 0.008 \\
\hline$<1 / 3$ & $54(27.0 \%)$ & $53(98.1 \%)$ & $1(1.9 \%)$ & \\
\hline $1 / 3-2 / 3$ & $61(31.0 \%)$ & $60(96.8 \%)$ & $2(3.2 \%)$ & \\
\hline$\geq 2 / 3$ & $84(42.0 \%)$ & $72(85.7 \%)$ & $12(14.3 \%)$ & \\
\hline Lymph nodes invasion & & & & 0.024 \\
\hline No & $154(77.0 \%)$ & $146(94.8 \%)$ & $8(5.2 \%)$ & \\
\hline Yes & $46(23.0 \%)$ & $39(84.8 \%)$ & $7(46.7 \%)$ & \\
\hline Parametrium invasion & & & & 0.599 \\
\hline No & $181(90.5 \%)$ & $168(92.8 \%)$ & $13(7.2 \%)$ & \\
\hline Yes & 19 (9.5\%) & 17 (89.5\%) & $2(10.5 \%)$ & \\
\hline Surgical margin & & & & $<0.001$ \\
\hline No & 187 (93.5\%) & 177 (94.7\%) & $10(5.3 \%)$ & \\
\hline Yes & $13(6.5 \%)$ & $8(61.5 \%)$ & $5(38.5 \%)$ & \\
\hline Treatment & & & & 0.235 \\
\hline Surgery & $83(41.5 \%)$ & 80 (96.4\%) & $3(3.6 \%)$ & \\
\hline Surgery + chemotherapy & $21(10.5 \%)$ & $20(95.2 \%)$ & $1(4.8 \%)$ & \\
\hline
\end{tabular}




\begin{tabular}{|c|c|c|c|}
\hline Characteristic & Total $(n=200)$ & HPVA $(n=186)$ & $\operatorname{NHPVA}(n=16)$ \\
\hline Surgery + radiotherapy & $41(20.5 \%)$ & $36(87.8 \%)$ & $5(12.2 \%)$ \\
\hline Surgery + chemoradiation & $55(27.5 \%)$ & 49 (89.1\%) & $6(10.9 \%)$ \\
\hline MMR status & & & 0.978 \\
\hline dMMR & $13(6.5 \%)$ & $12(92.3 \%)$ & $1(7.7 \%)$ \\
\hline pMMR & $187(93.5 \%)$ & $173(92.5 \%)$ & $14(7.5 \%)$ \\
\hline P16 IHC & & & 0.001 \\
\hline Negative & $82(41.0 \%)$ & $70(85.4 \%)$ & $12(14.6 \%)$ \\
\hline Positive & $118(59.0 \%)$ & $115(97.5 \%)$ & $3(2.5 \%)$ \\
\hline Ki-67 IHC & & & 0.131 \\
\hline$\leq 12.5 \%$ & $48(24 \%)$ & $42(87.5 \%)$ & $6(12.5 \%)$ \\
\hline$>12.5 \%$ & $152(76 \%)$ & $143(94.1 \%)$ & $9(5.9 \%)$ \\
\hline
\end{tabular}

Diagnostic performance of HPV E6/E7 mRNA in situ hybridization in ECA compared to other assays.

The RNAscope scores of 0 to 4 are shown in Fig. 1A and 1B. The diagnostic implications of the HPV E6/E7 RNAscope scores were evaluated in 200 ECA samples that included both HPVA and NHPVA cases (Table S1). The positive rates of HPV DNA, p16 IHC, HPV genotype, and HPV E6/E7 RNAscope across all ECA cases were 76.4\%, 59.0\%, 62.5\%, and 72.0\%, respectively (Fig. 1C and Fig. S3). HPV RNAscope and other assays were closely related (Table S2). ROC curves suggested that HPV DNA and HPV E6/E7 RNAscope showed similar results in terms of distinguishing HPVA from NHPVA (area under the curve $[A U C]=0.802$, sensitivity $=80.5 \%$, specificity $=80 \%$ vs. $A U C=0.799$, sensitivity $=75.8 \%$, specificity $=80 \%$, respectively), outperforming both p16 IHC (AUC $=0.751$, sensitivity $=60.2 \%$, specificity $=90 \%)$ and HPV genotype $(A \cup C=0.566$, sensitivity $=63.3 \%$, specificity $=50 \%$; Fig. $1 \mathrm{D}$ and Table 5$)$.

The correlations among serum HPV DNA level, p16 IHC, HPV genotype, and HPV E6/E7 RNAscope were also studied (Table S2). A significantly higher proportion of ECA cases were positive for p16 IHC, HPV genotype, and HPV E6/E7 RNAscope in subgroups with HPV DNA levels that differed by 10-fold. In patients with serum HPV DNA levels of $1-100 \mathrm{pg} / \mathrm{mL}$, the $\mathrm{p} 16 \mathrm{IHC}$ positivity was similar to that of HPV genotype (60\%), while those with serum HPV DNA levels of $100-10,000 \mathrm{pg} / \mathrm{mL}, \mathrm{HPV}$ genotype positivity was similar to that of HPV E6/E7 RNAscope (93.8\%). The HPV E6/E7 RNAscope positivity for the diagnosis of ECA was much higher compared to p16 IHC and HPV genotype (Fig. S4A). We also elicited that HPV E6/E7 RNAscope was positive in almost all cases that were $\mathrm{p} 16 \mathrm{IHC}$ positive ( $88.5 \%$ of all cases, 89.5\% of HPVA cases), only that more cases were negative by IHC and serum levels (Fig. S4B). In 
different HPV subtypes, the positivity of RNAscope for the diagnosis of ECA was much higher compared to that of p16 IHC, but lower than HPV DNA (Fig. S4C). The HPV subtypes in patients with HPVA and NHPVA are listed in Table S3. In cases with RNAscope scores of 3 and 4, the HPV DNA positivity was higher than both p16 IHC and HPV genotype (Fig. S4D).

\section{Multivariate analysis of overall survival}

Univariate analysis indicated that the following variables were related to OS in patients with ECA: age ( $p=$ 0.002), HPV E6/E7 RNAscope ( $p=0.006)$, tumor size $(p=0.005)$, FIGO stage $(p<0.001)$, histological type $(p=0.004), \operatorname{LVI}(p<0.001)$, invasion level of uterine cervix $(p<0.001), \operatorname{LNI}(p<0.001)$, parametrium invasion $(p<0.001)$, surgical margin $(p=0.006)$, chemotherapy $(p=0.009)$, radiotherapy $(p<0.001)$, p16 $(p=0.039)$, and Ki-67 ( $p=0.025)$. In a multivariate analysis, the following items remained independently prognostic: age (HR= 0.250,95\% confidence interval [Cl]: 0.099-0.632, $p=0.003)$, HPV E6/E7 RNAscope $(\mathrm{HR}=0.240,95 \% \mathrm{Cl}: 0.093-0.616, \mathrm{p}=0.003), \mathrm{LVI}(\mathrm{HR}=1.924,95 \% \mathrm{Cl}: 1.295-2.857, \mathrm{p}=0.001)$, and LNI $(\mathrm{HR}=3.047,95 \% \mathrm{Cl}: 1.183-7.849, \mathrm{p}=0.021)$. The results are shown in Table 2, with a forest plot in Fig. 2A. Kaplan-Meier analysis showed significant diversity (Fig. 2B-E). 
Table 2

Univariate and multivariate Cox proportional hazards regression analysis for OS.

\begin{tabular}{|c|c|c|c|c|}
\hline \multirow[t]{2}{*}{ Variables } & \multicolumn{2}{|c|}{ Univariate analysis } & \multicolumn{2}{|c|}{ Multivariate analysis } \\
\hline & $\mathrm{HR}(95 \% \mathrm{Cl})$ & $\begin{array}{l}P \\
\text { value }\end{array}$ & $\mathrm{HR}(95 \% \mathrm{Cl})$ & $\begin{array}{l}P \\
\text { value }\end{array}$ \\
\hline Age ( $\leq 37$ vs. $>37$ years) & $\begin{array}{l}0.316(0.154- \\
0.649)\end{array}$ & 0.002 & $\begin{array}{l}0.224(0.095- \\
0.530)\end{array}$ & 0.001 \\
\hline HPV DNA (negative vs. positive vs. na) & $\begin{array}{l}0.868(0.500- \\
1.509)\end{array}$ & 0.616 & & \\
\hline $\begin{array}{l}\text { HPV genotype (negative vs. positive vs. } \\
\text { na) }\end{array}$ & $\begin{array}{l}1.004(0.523- \\
1.926)\end{array}$ & 0.992 & & \\
\hline HPV RNAscope ( $\leq 3.3$ vs. >3.3) & $\begin{array}{l}0.337(0.156- \\
0.730)\end{array}$ & 0.006 & $\begin{array}{l}0.288(0.124- \\
0.673)\end{array}$ & 0.004 \\
\hline Tumor size ( $\leq 4.5$ vs. $>4.5 \mathrm{~cm})$ & $\begin{array}{l}3.165(1.414- \\
7.083)\end{array}$ & 0.005 & $\begin{array}{l}0.773(0.223- \\
2.674)\end{array}$ & 0.684 \\
\hline FIGO stage (I vs. II vs. III vs. IV) & $\begin{array}{l}2.821(1.703- \\
4.672)\end{array}$ & $\hat{0} 001$ & $\begin{array}{l}1.120(0.613- \\
2.013)\end{array}$ & 0.705 \\
\hline Histological type (HPVA vs. NHPVA) & $\begin{array}{l}0.266(0.108- \\
0.657)\end{array}$ & 0.004 & $\begin{array}{l}1.365(0.334- \\
5.589)\end{array}$ & 0.665 \\
\hline $\begin{array}{l}\text { Differentiation (good vs. moderate vs. } \\
\text { poor) }\end{array}$ & $\begin{array}{l}1.435(0.768- \\
2.684)\end{array}$ & 0.258 & & \\
\hline $\begin{array}{l}\text { LVI (none vs. focal vs. moderate vs. } \\
\text { extensive) }\end{array}$ & $\begin{array}{l}2.056(1.508- \\
2.803)\end{array}$ & $\hat{0} .001$ & $\begin{array}{l}1.770(1.212- \\
2.587)\end{array}$ & 0.003 \\
\hline $\begin{array}{l}\text { Invasion level of uterine cervix ( } 1 / 3 \text { vs. } \\
1 / 3-2 / 3 \text { vs. } 2 / 3 \text { ) }\end{array}$ & $\begin{array}{l}3.147(1.754- \\
5.648)\end{array}$ & $\hat{0} 001$ & $\begin{array}{l}1.532(0.791- \\
2.967)\end{array}$ & 0.206 \\
\hline Lymph nodes invasion (no vs. yes) & $\begin{array}{l}9.310(4.533- \\
19.120)\end{array}$ & $<.001$ & $\begin{array}{l}2.838(1.162- \\
6.931)\end{array}$ & 0.022 \\
\hline Parametrium invasion (no vs. yes) & $\begin{array}{l}0.231(0.094- \\
0.568)\end{array}$ & 0.001 & $\begin{array}{l}0.696(0.217- \\
2.234)\end{array}$ & 0.543 \\
\hline Surgical margin (no vs. yes) & $\begin{array}{l}0.263(0.101- \\
0.687)\end{array}$ & 0.006 & $\begin{array}{l}1.621(0.435- \\
6.048)\end{array}$ & 0.472 \\
\hline Treatment (s vs. s + ct vs. s+rt vs. s + cr) & $\begin{array}{l}1.733(1.298- \\
2.313)\end{array}$ & $\grave{0.001}$ & $\begin{array}{l}1.182(0.851- \\
1.641)\end{array}$ & 0.318 \\
\hline MMR status (dMMR vs. pMMR) & $\begin{array}{l}1.401(0.426- \\
4.610)\end{array}$ & 0.579 & & \\
\hline
\end{tabular}

HR, hazard ratio; $\mathrm{Cl}$, confidence interval. HPVA, HPV-associated adenocarcinoma; NHPVA, non HPVassociated adenocarcinoma; IHC, immunohistochemistry; LVI, lymph vascular invasion; dMMR, delete mismatch repair; pMMR, proficient mismatch repair; HPV genotype positive, HPV16, HPV18 and other types; s, surgery; s c ct, surgery + chemotherapy; s + rt, surgery + radiotherapy; s + cr, surgery + chemoradiation; na, not avaiable. 


\begin{tabular}{|c|c|c|c|c|}
\hline \multirow[t]{2}{*}{ Variables } & \multicolumn{2}{|c|}{ Univariate analysis } & \multicolumn{2}{|c|}{ Multivariate analysis } \\
\hline & $\mathrm{HR}(95 \% \mathrm{Cl})$ & $\begin{array}{l}P \\
\text { value }\end{array}$ & $\mathrm{HR}(95 \% \mathrm{Cl})$ & $\begin{array}{l}P \\
\text { value }\end{array}$ \\
\hline P16 IHC (negative vs. positive) & $\begin{array}{l}0.478(0.237- \\
0.963)\end{array}$ & 0.039 & $\begin{array}{l}1.203(0.507- \\
2.854)\end{array}$ & 0.675 \\
\hline Ki-67 IHC ( $\leq 12.5 \%$ vs. $>12.5 \%)$ & $\begin{array}{l}0.446(0.220- \\
0.906)\end{array}$ & 0.025 & $\begin{array}{l}0.841(0.348- \\
2.035)\end{array}$ & 0.701 \\
\hline \multicolumn{5}{|c|}{$\begin{array}{l}\text { HR, hazard ratio; Cl, confidence interval. HPVA, HPV-associated adenocarcinoma; NHPVA, non HPV- } \\
\text { associated adenocarcinoma; IHC, immunohistochemistry; LVI, Iymph vascular invasion; dMMR, delete } \\
\text { mismatch repair; pMMR, proficient mismatch repair; HPV genotype positive, HPV16, HPV18 and other } \\
\text { types; s, surgery; } \mathrm{s}+\mathrm{ct} \text {, surgery + chemotherapy; } \mathrm{s}+\mathrm{rt} \text {, surgery + radiotherapy; }+\mathrm{cr} \text {, surgery + } \\
\text { chemoradiation; na, not avaiable. }\end{array}$} \\
\hline
\end{tabular}

Construction of the prognostic nomogram model and comparison of predictive accuracy between Nomogram model, FIGO stage and treatment.

Two different nomograms that predict the OS of ECA patients were built and compared for efficiency. Nomogram A included age, HPV E6/E7 RNAscope, LVI, and LNI, while nomogram B included age, HPV E6/E7 RNAscope, LVI, LNI, FIGO stage, and treatment. The results of time-dependent ROC curve for OS showed that AUCs of nomogram A and FIGO stage were higher than treatment (Fig. 3A). The resulting variables from the Cox proportional analysis were used to build the prognostic nomograms for OS (Fig. 3B and 3C). Each prognostic factor within the nomogram was assigned a point. By sum of the total points from all variables combined with the location the total point scale allowed us to obtain the probabilities of the outcomes by drawing a vertical line towards the axis labeled "1-, 3-, 5-Year survival probability" (Fig. 3B and 3C). The results of the comparison of efficiency between our nomogram and the conventional systems are shown in Table 3. In the two nomograms, no significant difference was observed (C-index: $0.825,95 \% \mathrm{Cl}=0.754-0.896$ vs. $0.836,95 \% \mathrm{Cl}=0.771-0.902)$. The $\mathrm{C}$-index of nomogram $\mathrm{A}(0.825,95 \% \mathrm{Cl}=0.754-0.896)$ was better than those of the FIGO system $(0.653,95 \% \mathrm{Cl}=$ $0.567-0.740)$ and treatment $(0.578,95 \% \mathrm{Cl}=0.506-0.651)$. In Fig. $4 \mathrm{~A}$ and $4 \mathrm{~B}$, the calibration plot for the OS rates for 1,3, and 5-years was in line with both the nomogram and the actual observation. Besides, our model seemed to have a higher prediction accuracy (Fig. 4C). 
Table 3

The C-index of our model, FIGO stage, Treatment for prediction of OS in the ECA.

\begin{tabular}{|llll|}
\hline Factors & C-index & $95 \mathrm{Cl} \%$ & $\boldsymbol{P}$ \\
\hline Nomogram A & 0.825 & $0.754-0.896$ & \\
\hline FIGO stage & 0.653 & $0.567-0.740$ & \\
\hline Treatment & 0.578 & $0.506-0.651$ & \\
\hline Nomogram B & 0.836 & $0.771-0.902$ & \\
\hline Nomogram A vs FIGO stage & & 0.002 \\
\hline Nomogram A vs Treatment & & $<.001$ \\
\hline Nomogram A vs Nomogram B & & 0.139 \\
\hline Nomogram A: age + HPV RNA scope + LVI+ LNI & & \\
\hline Nomogram B: age + HPV RNA scope+ LVI + LNI + FIGO stage + Treatment & \\
\hline $\begin{array}{l}\text { C-index = concordance index; LVI, lymph vascular invasion; LNI, lymph node involvement; P values are } \\
\text { calculated based on normal approximation using function rcorrp.cens in Hmisc package. }\end{array}$ \\
\hline
\end{tabular}

\section{Risk stratification of prognosis}

All patients were divided into a low $(\leq 15.75)$ and a high-risk group (>15.75) for OS (Fig. S2B). The 1,3, and 5-year OS rates were $94.2 \%, 84.3 \%, 70.3 \%$, respectively, in the low-risk group and $71.4 \%, 46.4 \%, 10.7 \%$, respectively, in the high-risk group (Table 4). Moreover, significant differences in OS were noted between patients with stage I/II ECA and those with III/IV ECA (Fig. 5). Each risk subgroup represented a distinct prognosis, and our system accurately separated the OS rates of the two subgroups.

Table 4. Point Assignment and Prognostic Score of the nomogram model 


\begin{tabular}{|lllll|}
\hline Variables & Prognostic Score & 1-Year OS (\%) & 3-Year OS (\%) & 5-Year OS (\%) \\
\hline Age (years) & & & & \\
\hline$\leq 37$ & 7.5 & 11.8 & 26.5 & 35.3 \\
\hline$>37$ & 0 & 1.8 & 6.0 & 10.8 \\
\hline HPV RNA scope & & & & \\
\hline$\leq 3.3$ & 7 & 5.1 & 13.1 & 21.2 \\
\hline$>3.3$ & 0 & 2.0 & 5.9 & 8.9 \\
\hline Lymph nodes invasion & & & & \\
\hline No & 0 & 1.9 & 4.5 & 7.1 \\
\hline Yes & 8.25 & 8.7 & 26.1 & 41.3 \\
\hline Lymph vascular invasion & & & & 10.1 \\
\hline None & 0 & 1.4 & 6.5 & 13.5 \\
\hline Focal & 3.25 & 2.7 & 10.8 & 26.7 \\
\hline Moderate & 6.5 & 13.3 & 20.0 & 70.0 \\
\hline Extensive & 9.75 & 20.0 & 30.0 & 70.3 \\
\hline Total prognostic Score & & 94.2 & 84.3 & 10.7 \\
\hline$\leq 15.75$ & & 71.4 & 46.4 & \\
\hline$>15.75$ & & & & \\
\hline
\end{tabular}


Table 5

Diagnostic performances of studied testing for ECA patients.

Table Table 4. Point Assignment and Prognostic Score of the nomogram model

\begin{tabular}{|c|c|c|c|c|}
\hline Variables & Prognostic Score & 1 -Year OS (\%) & 3-Year OS (\%) & 5-Year OS (\%) \\
\hline \multicolumn{5}{|l|}{ Age (years) } \\
\hline$\leq 37$ & 7.5 & 11.8 & 26.5 & 35.3 \\
\hline$>37$ & 0 & 1.8 & 6.0 & 10.8 \\
\hline
\end{tabular}

HPV RNA scope

$\begin{array}{lllll}\leq 3.3 & 7 & 5.1 & 13.1 & 21.2 \\ >3.3 & 0 & 2.0 & 5.9 & 8.9\end{array}$

Lymph nodes invasion

$\begin{array}{lllll}\text { No } & 0 & 1.9 & 4.5 & 7.1 \\ \text { Yes } & 8.25 & 8.7 & 26.1 & 41.3\end{array}$

Lymph vascular invasion

\begin{tabular}{lllll} 
None & 0 & 1.4 & 6.5 & 10.1 \\
\hline Focal & 3.25 & 2.7 & 10.8 & 13.5 \\
\hline Moderate & 6.5 & 13.3 & 20.0 & 26.7 \\
\hline Extensive & 9.75 & 20.0 & 30.0 & 70.0 \\
\hline Total prognostic Score & & & & \\
\hline$\leq 15.75$ & & 94.2 & 84.3 & 70.3 \\
\hline$>15.75$ & AUC & 71.4 & 46.4 & 10.7 \\
HPVA vs. NHPVA & 0.751 & $95 \% \mathrm{Cl}$ & Sensitivity & Specificity \\
\hline P16 IHC & 0.802 & $0.620-0.882$ & 0.602 & 0.900 \\
\hline HPV DNA & $0.653-0.951$ & 0.805 & 0.800 \\
\hline HPV genotype & 0.566 & $0.379-0.754$ & 0.633 & 0.500 \\
\hline HPV RNAscope & 0.799 & $0.629-0.929$ & 0.758 & 0.800
\end{tabular}

AUC, area under curve; 95\% Cl, 95\% confident interval; HPVA, HPV-associated adenocarcinoma; NHPVA, nonHPV-associated adenocarcinoma; IHC, immunohistochemistry; HPV RNAscope. 
Our study is the first of its kind to describe a prognostic nomogram model for invasive ECA in a large Chinese series by reporting HPV E6/E7 RNAscope using a new RNA ISH assay that recognizes 18 highrisk HPV types. The most important finding of our research are as follows: (1) the validity of the HPVA and NHPVA categories were supported by p16 immunophenotyping and HPV status; (2) HPV E6/E7 RNAscope is more sensitive and specific than p16 and HPV genotype in identifying HPVA; (3) we established a prognostic nomogram model based on ECA pathogenesis that adjusted for age, LVI, HPV E6/E7 RNAscope, and LNI, which had a greater predictive efficiency than the current conventional staging system; (4) in the future, we believe, based on our model, ECA patients could be divided into low and highrisk groups.

HPV E6/E7 RNAscope measurement is not routinely available in most hospitals; hence the methodology cannot be extrapolated to standard practice. About $94 \%$ of adenocarcinomas are associated with HPV, particularly high risk strains like 16 and 18[5], which is consistent with our results. In the present study, $87 \%(160 / 184)$ of HPVA samples overexpressed $\mathrm{p} 16$ or were HPV positive by RNAscope, validating the IECC criteria and previous studies[9, 20]. In terms of the IECC criteria, the HPV RNAscope is more specific for clinical practice, and it is more robust than p16 IHC, HPV DNA, and HPV genotype in identifying HPVA. Despite this, occasional p16 and/or HPV negative HPVAs were also identified. When outlying cases were excluded from the statistical analysis, 25 of the 184 HPVA cases were p16- and HPV-positive. All HPVA cases in the present study were systematically reviewed.. The specimens were more than 5 years old and may not have been optimal tissues for the performance of HPV RNAscope and p16. A recent study reported that the HPV associated ECA might represent unusual morphological variants of gastric-type carcinoma[21]. Furthermore, rare HPV genotypes not included in the RNA ISH probe set may be responsible for the negative HPV results. There are precedents in the literature for p16-and HPVassociated neoplasia. Notably, p16-positive invasive squamous carcinomas of the cervix have been reported[22] to be closely associated with methylation-induced inactivation of the p16 gene and allelic loss of $p 16[23,24]$. Other studies have reported that the HPV genome can be differentially expressed with varying heterogeneity between the primary and the metastatic sites suggesting that some HPV-related usual-type adenocarcinomas could have detectable HPV in multiple sections of primary carcinoma; hence all metastatic sites should be tested[20, 25, 26].

Clinicopathological variables carry a prognostic significance and usually affect clinical management[27, 28]. Depending on variables such as LVI and desire for fertility, histological-based risk evaluation should be considered during tissue sampling at initial diagnosis[15, 29]. The National Comprehensive Cancer Network guidelines recommend chemotherapy or radiotherapy as the standard treatment for patients with advanced ECA, hence, the performance of nomograms must be examined separately in patients treated using these therapies. The $\mathrm{C}$-indices of nomograms $\mathrm{A}$ and $\mathrm{B}$ for predicting OS in treated patients were significantly higher than those of conventional classification, indicating that nomograms still have significant clinical value in patients with ECA. With the addition of the FIGO stage and treatment into nomogram $B$, the added values of these parameters over nomogram A were 0.836 and 0.825 , respectively, across the entire population. There were no significant differences between nomograms $A$ and $B$, probably due to the small sample size of patients with advanced-stage ECA. 
The present study had several limitations. Firstly, there may have been selection bias in our patient cohort. Secondly, we lacked data on the impact of our nomogram on other prognostic endpoints, such as disease-free survival (DFS) prediction. Thirdly, in situ measurement of HPV RNA using RNAscope is not easily available and not globally standardized. Fourthly, our sample size was relatively small and from only one center. In order to validate our results, a study with a larger sample with multicenter data is required. Lastly, it remains unclear whether our nomogram can be applied to ECA patients with advancedstage that is, stage III and IV.

\section{Conclusions}

We generated new nomograms that incorporate HPV E6/E7 mRNA in situ hybridization and patients' clinical characteristics in order to prognosticate the OS rate in ECA patients. Our simple and explicit nomograms have a good clinical application value, with a good diagnostic discernment and calibration ability. They may be a useful tool for assessing the prognosis and the management of ECA patients.

\section{Abbreviations}

\section{HPV}

Human papillomavirus; HPV E6/E7 RNAscope:Human papillomavirus E6/E7 mRNA in situ hybridization; ECA:Endocervical adenocarcinoma; C-index:Concordance index; HPVA:HPV-associated adenocarcinoma; NHPVA:non-HPV-associated adenocarcinoma; OS:Overall survival; LVI:Lymphovascular invasion; LNl:Lymph node involvement.

\section{Declarations}

\section{Ethics approval and consent to participate}

The Sun Yat-sen University Cancer Center Ethics Committee approved this study.

\section{Consent for publication}

\section{Not applicable.}

\section{Availability of data and materials}

The authenticity of this article has been validated by uploading the key raw data onto the Research Data Deposit public platform (www.researchdata.org.cn) with the approval RDD number RDDA2020001638.

\section{Competing interests}

The authors declare that they have no competing interests.

\section{Funding}


This work was supported by the National Natural Science Foundation of China (No. 82072853). The Natural Science Foundation of Guangdong province (No. 2021A1515010688).

\section{Authors' contributions}

Conception and design: Li-Li Liu. Performing experiments: Mei Li, Yue Li and Xia Yang. Drafting of the article: Rong-Zhen Luo and Shu-Lin Chen. Acquisition and interpretation of data, review, editing and approval of the manuscript: all authors.

\section{Acknowledgments}

The authors gratefully acknowledge the assistance from professor Jing-Ping Yun from Sun Yat-sen University Cancer Center.

\section{References}

1. Ward KK, Shah NR, Saenz CC, McHale MT, Alvarez EA, Plaxe SC. Changing demographics of cervical cancer in the United States (1973-2008). Gynecol Oncol. 2012;126(3):330-3.

2. Galic V, Herzog TJ, Lewin SN, Neugut Al, Burke WM, Lu YS, Hershman DL, Wright JD. Prognostic significance of adenocarcinoma histology in women with cervical cancer. Gynecol Oncol. 2012;125(2):287-91.

3. Bhatla N, Berek JS, Cuello Fredes M, Denny LA, Grenman S, Karunaratne K, Kehoe ST, Konishi I, Olawaiye AB, Prat J, et al. Revised FIGO staging for carcinoma of the cervix uteri. Int J Gynaecol Obstet. 2019;145(1):129-35.

4. Stolnicu S, Hoang L, Chiu D, Hanko-Bauer O, Terinte C, Pesci A, Aviel-Ronen S, Kiyokawa T, AlvaradoCabrero I, Oliva E, et al. Clinical Outcomes of HPV-associated and Unassociated Endocervical Adenocarcinomas Categorized by the International Endocervical Adenocarcinoma Criteria and Classification (IECC). Am J Surg Pathol. 2019;43(4):466-74.

5. RJ K, ML C, CS H, RH Y: WHO Classification of Tumors of Female Reproductive Organs, 4th ed. Lyon: IARC, WHO Press 2014.

6. Byun JM, Cho HJ, Park HY, Kim YN, Lee KB, Sung MS, Jeong CH, Jeong DH. Clinical significance of the pattern-based classification in endocervical adenocarcinoma, usual and variants. Int $\mathrm{J}$ Clin Oncol. 2019;24(10):1264-72.

7. Karamurzin YS, Kiyokawa T, Parkash V, Jotwani AR, Patel P, Pike MC, Soslow RA, Park KJ. Gastrictype Endocervical Adenocarcinoma: An Aggressive Tumor With Unusual Metastatic Patterns and Poor Prognosis. Am J Surg Pathol. 2015;39(11):1449-57.

8. Stolnicu S, Barsan I, Hoang L, Patel P, Terinte C, Pesci A, Aviel-Ronen S, Kiyokawa T, Alvarado-Cabrero I, Oliva E, et al. Stromal invasion pattern identifies patients at lowest risk of lymph node metastasis in HPV-associated endocervical adenocarcinomas, but is irrelevant in adenocarcinomas unassociated with HPV. Gynecol Oncol. 2018;150(1):56-60. 
9. Stolnicu S, Barsan I, Hoang L, Patel P, Terinte C, Pesci A, Aviel-Ronen S, Kiyokawa T, Alvarado-Cabrero I, Pike MC, et al. International Endocervical Adenocarcinoma Criteria and Classification (IECC): A New Pathogenetic Classification for Invasive Adenocarcinomas of the Endocervix. Am J Surg Pathol. 2018;42(2):214-26.

10. Cheung TH, Yim SF, Yu MY, Worley MJ Jr, Fiascone SJ, Chiu RWK, Lo KWK, Siu NSS, Wong MCS, Yeung ACM, et al. Liquid biopsy of HPV DNA in cervical cancer. J Clin Virol. 2019;114:32-6.

11. McCluggage WG, Jenkins D. p16 immunoreactivity may assist in the distinction between endometrial and endocervical adenocarcinoma. Int J Gynecol Pathol. 2003;22(3):231-5.

12. Kenemans P. HPV genotype as a prognostic factor for progression to cervical carcinoma in young women. Eur J Obstet Gynecol Reprod Biol. 1994;55(1):24-5.

13. Schache AG, Liloglou T, Risk JM, Jones TM, Ma XJ, Wang H, Bui S, Luo Y, Sloan P, Shaw RJ, et al. Validation of a novel diagnostic standard in HPV-positive oropharyngeal squamous cell carcinoma. Br J Cancer. 2013;108(6):1332-9.

14. Mirghani H, Casiraghi O, Amen F, He M, Ma XJ, Saulnier P, Lacroix L, Drusch F, Ben Lakdhar A, Saint Guily JL, et al. Diagnosis of HPV-driven head and neck cancer with a single test in routine clinical practice. Mod Pathol. 2015;28(12):1518-27.

15. Diaz De Vivar A, Roma AA, Park KJ, Alvarado-Cabrero I, Rasty G, Chanona-Vilchis JG, Mikami Y, Hong SR, Arville B, Teramoto N, et al. Invasive endocervical adenocarcinoma: proposal for a new patternbased classification system with significant clinical implications: a multi-institutional study. Int $\mathrm{J}$ Gynecol Pathol. 2013;32(6):592-601.

16. Roma AA, Park KJ, Xie H, De Vivar AD, Alvarado-Cabrero I, Rutgers JKL, Barbuto D, Silva EG. Role of Lymphovascular Invasion in Pattern C Invasive Endocervical Adenocarcinoma. Am J Surg Pathol. 2017;41(9):1205-11.

17. Anderson CM, Zhang B, Miller M, Butko E, Wu X, Laver T, Kernag C, Kim J, Luo Y, Lamparski H, et al. Fully Automated RNAscope In Situ Hybridization Assays for Formalin-Fixed Paraffin-Embedded Cells and Tissues. J Cell Biochem. 2016;117(10):2201-8.

18. Bakheet AMH, Zhao C, Chen JN, Zhang JY, Huang JT, Du Y, Gong LP, Bi YH, Shao CK. Improving pathological early diagnosis and differential biomarker value for hepatocellular carcinoma via RNAscope technology. Hepatol Int. 2020;14(1):96-104.

19. Camp RL, Dolled-Filhart M, Rimm DL. X-tile: a new bio-informatics tool for biomarker assessment and outcome-based cut-point optimization. Clin Cancer Res. 2004;10(21):7252-9.

20. Molijn A, Jenkins D, Chen W, Zhang X, Pirog E, Enqi W, Liu B, Schmidt J, Cui J, Qiao Y, et al. The complex relationship between human papillomavirus and cervical adenocarcinoma. Int $\mathrm{J}$ Cancer. 2016;138(2):409-16.

21. Wada T, Ohishi Y, Kaku T, Aman M, Imamura H, Yasutake N, Sonoda K, Kato K, Oda Y. Endocervical Adenocarcinoma With Morphologic Features of Both Usual and Gastric Types: Clinicopathologic and Immunohistochemical Analyses and High-risk HPV Detection by In Situ Hybridization. Am J Surg Pathol. 2017;41(5):696-705. 
22. Masoudi H, Van Niekerk DJ, Gilks CB, Cheang M, Bilek K, Fischer U, Ehlen T, Miller D, Horn LC. Loss of p16 INK4 expression in invasive squamous cell carcinoma of the uterine cervix is an adverse prognostic marker. Histopathology. 2006;49(5):542-5.

23. Nuovo GJ, Plaia TW, Belinsky SA, Baylin SB, Herman JG. In situ detection of the hypermethylationinduced inactivation of the 16 gene as an early event in oncogenesis. Proc Natl Acad Sci U S A. 1999;96(22):12754-9.

24. Poetsch M, Hemmerich M, Kakies C, Kleist B, Wolf E, vom Dorp F, Hakenberg OW, Protzel C. Alterations in the tumor suppressor gene $\mathrm{p} 16$ (INK4A) are associated with aggressive behavior of penile carcinomas. Virchows Arch. 2011;458(2):221-9.

25. Beyer-Finkler E, Girardi F, Sillem M, Pfister H. Human papillomavirus DNA in genital cancers, metastases, and lymph nodes. Intervirology. 1995;38(3-4):173-80.

26. Liang WS, Aldrich J, Nasser S, Kurdoglu A, Phillips L, Reiman R, McDonald J, Izatt T, Christoforides A, Baker A, et al. Simultaneous characterization of somatic events and HPV-18 integration in a metastatic cervical carcinoma patient using DNA and RNA sequencing. Int J Gynecol Cancer. 2014;24(2):329-38.

27. Ronnett BM. Endocervical adenocarcinoma: selected diagnostic challenges. Mod Pathol. 2016;29(Suppl 1):12-28.

28. Baalbergen A, Ewing-Graham PC, Hop WC, Struijk P, Helmerhorst TJ. Prognostic factors in adenocarcinoma of the uterine cervix. Gynecol Oncol. 2004;92(1):262-7.

29. Pecorelli S. Revised FIGO staging for carcinoma of the vulva, cervix, and endometrium. Int $J$ Gynaecol Obstet. 2009;105(2):103-4.

\section{Figures}



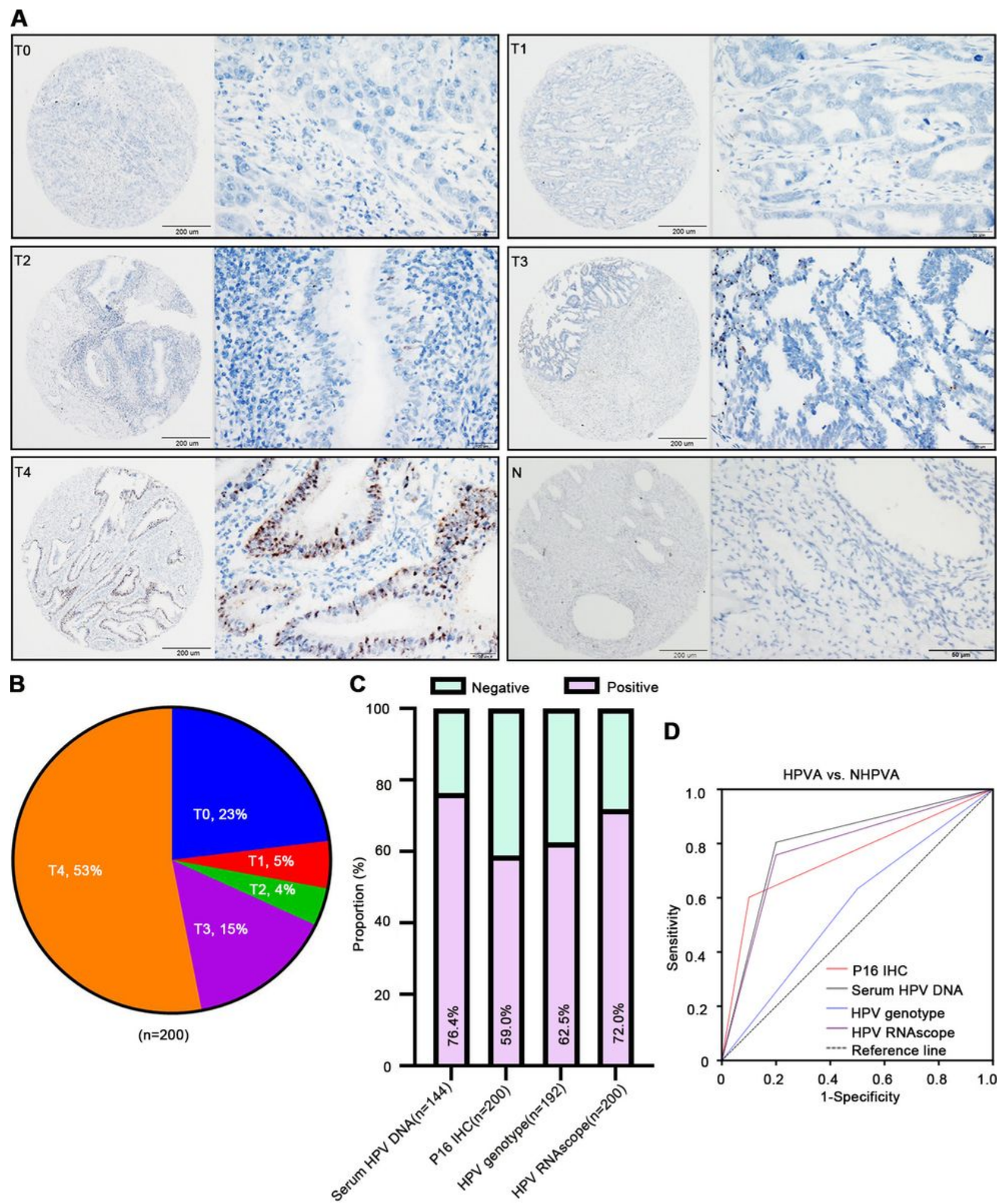

Figure 1

Representative images of human papillomavirus (HPV) E6/E7 RNAscope in paraffin-embedded endocervical adenocarcinoma (ECA) samples. (A) HPV mRNA was detected using RNAscope in ECA (T) and non-tumorous tissues adjacent to ECA (N). Representative images of scores 0 (T0), 1 (T1), 2 (T2), 3 (T3), and 4 (T4) are shown. (B) The proportion of RNAscope scores in ECA tissues. (C) Positive rates of HPV by PCR, RNAscope, HPV genotype, and p16 IHC. (D) Receiver operating characteristics curve for HPV, 
detected by PCR, immunohistochemistry, genotyping, and RNAscope for HPV-associated vs. non-HPVassociated types.

A
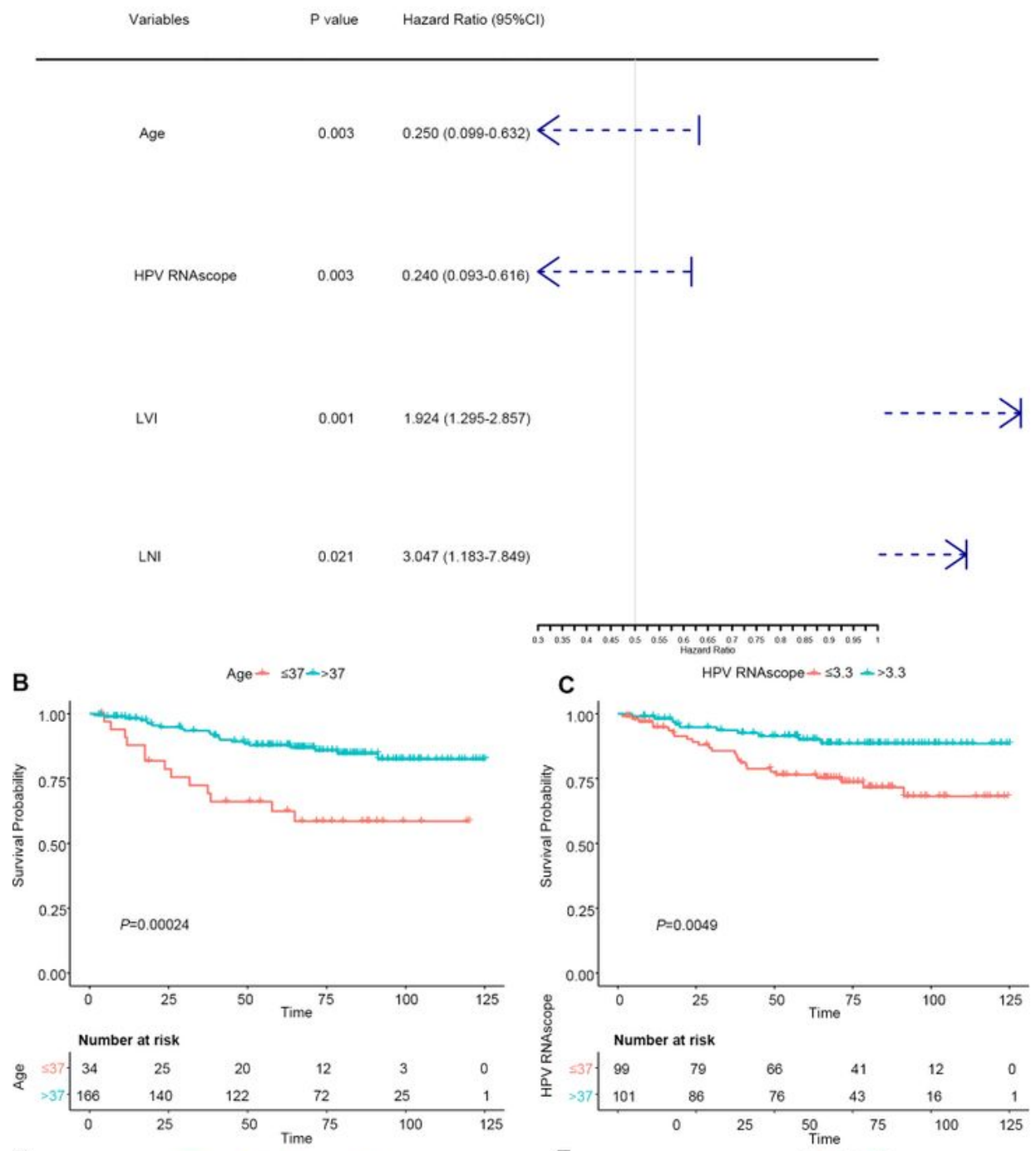

D
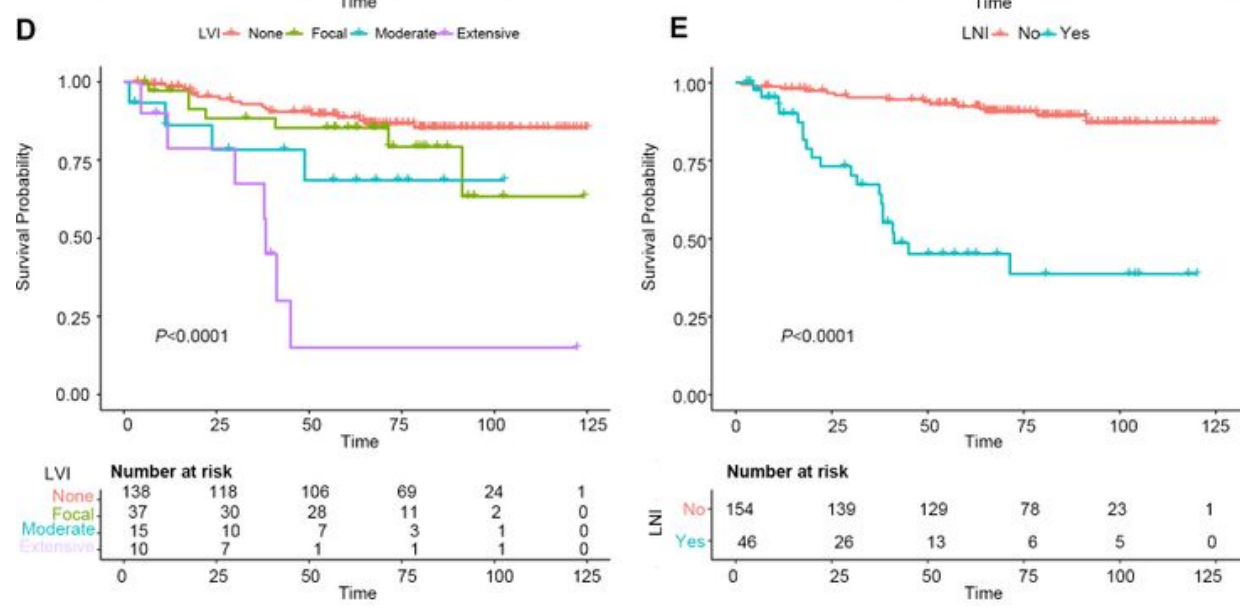

Figure 2

Forest plot and Kaplan-Meier curves for overall survival (OS) in patients with endocervical adenocarcinoma (ECA). (A) Forest plot showed the hazard ratio and $95 \%$ confidence interval for OS according to the Cox proportional hazards regression analysis in patients with ECA. (B-E) Age, human 
papillomavirus E6/E7 RNAscope, lymphovascular invasion, and lymph node involvement in patients with ECA in the whole cohort are plotted as a distribution.

A

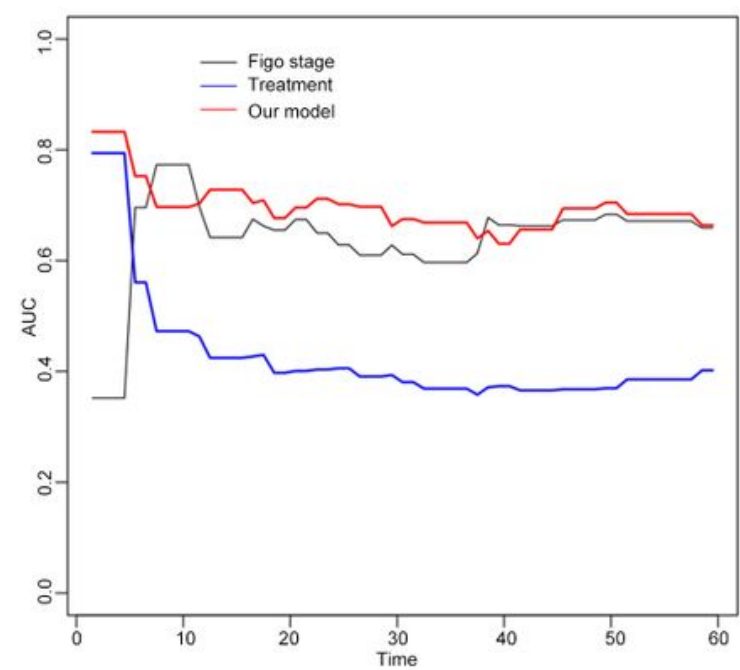

B

Points

Age

HPV RNAscope

LVI

LNI

Total Points

1-year survival

3-year survival

5-year survival

C

Points

Age

HPV RNAscope

LVI

LNI

FIGO stage

Treatment

Total Points

1-year survival

3-year survival

5-year survival
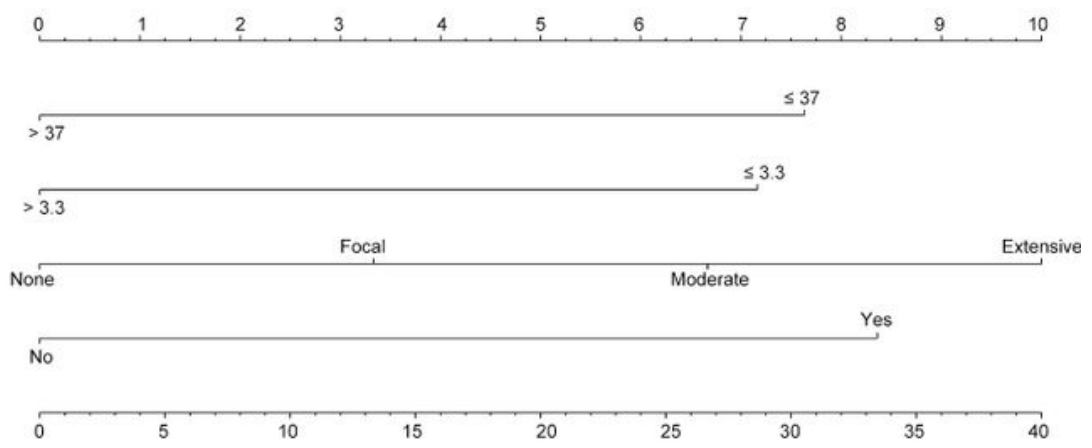

\begin{tabular}{lllllll}
\hline 0.95 & 0.9 & 0.8 & 0.7 & 0.6 & 0.5
\end{tabular}

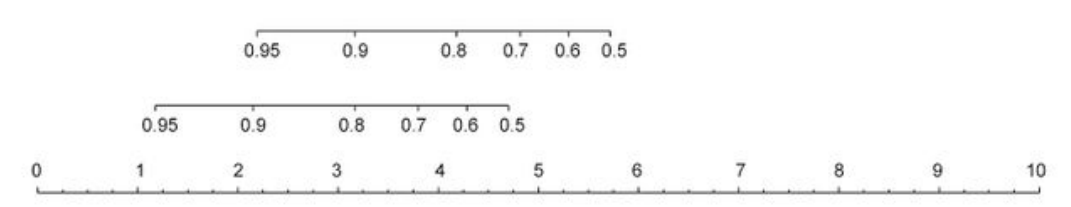

$$
>37
$$

$$
>3.3
$$

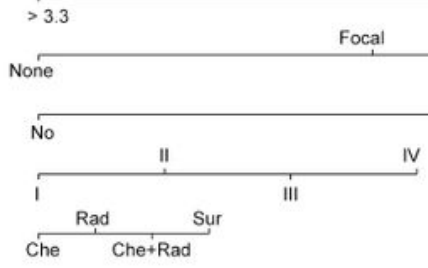

$5+5 \quad 10$

$\leq 37$

3.3

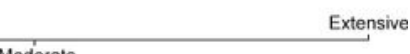

Yes

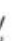

(1)

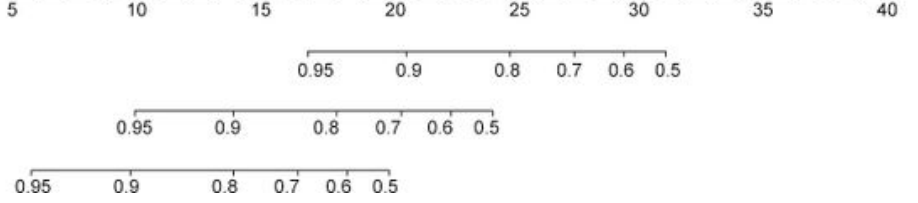

Figure 3

Time-dependent ROC curve analysis and nomogram model for overall survival (OS) in patients with endocervical adenocarcinoma ECA. (A) Time-dependent receiver operating characteristic curves showing the sensitivity and specificity of the nomogram model for predicting OS. (B-C) The nomogram models A 
and $B$ were used to summate the points identified on the points scale for each variable, indicating the probability of 1-, 3-, and 5-year survival.

A

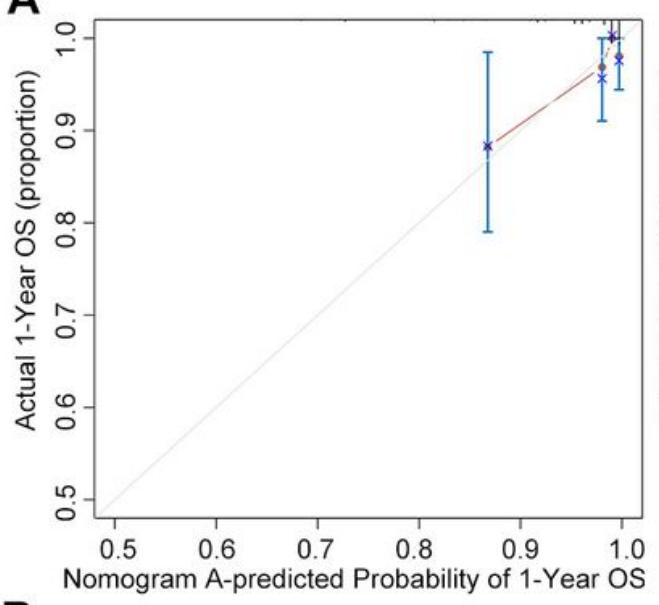

B

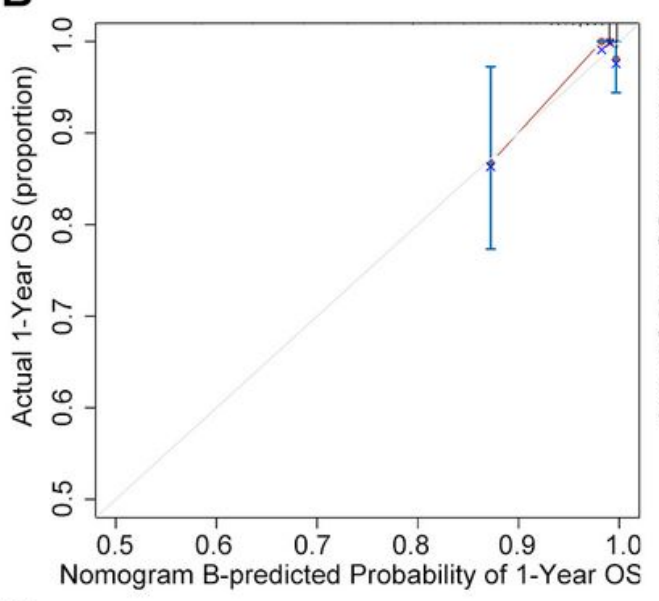

C

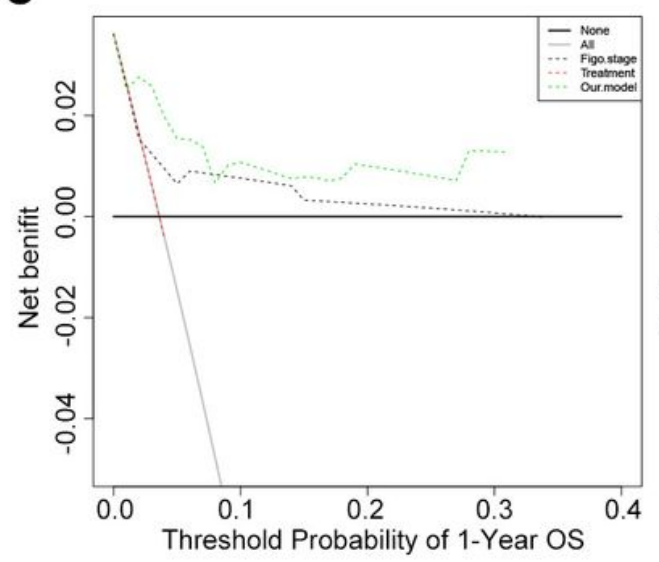

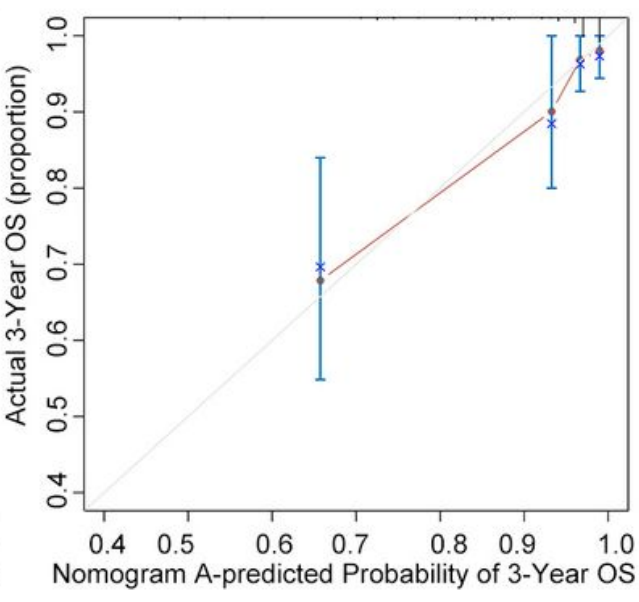
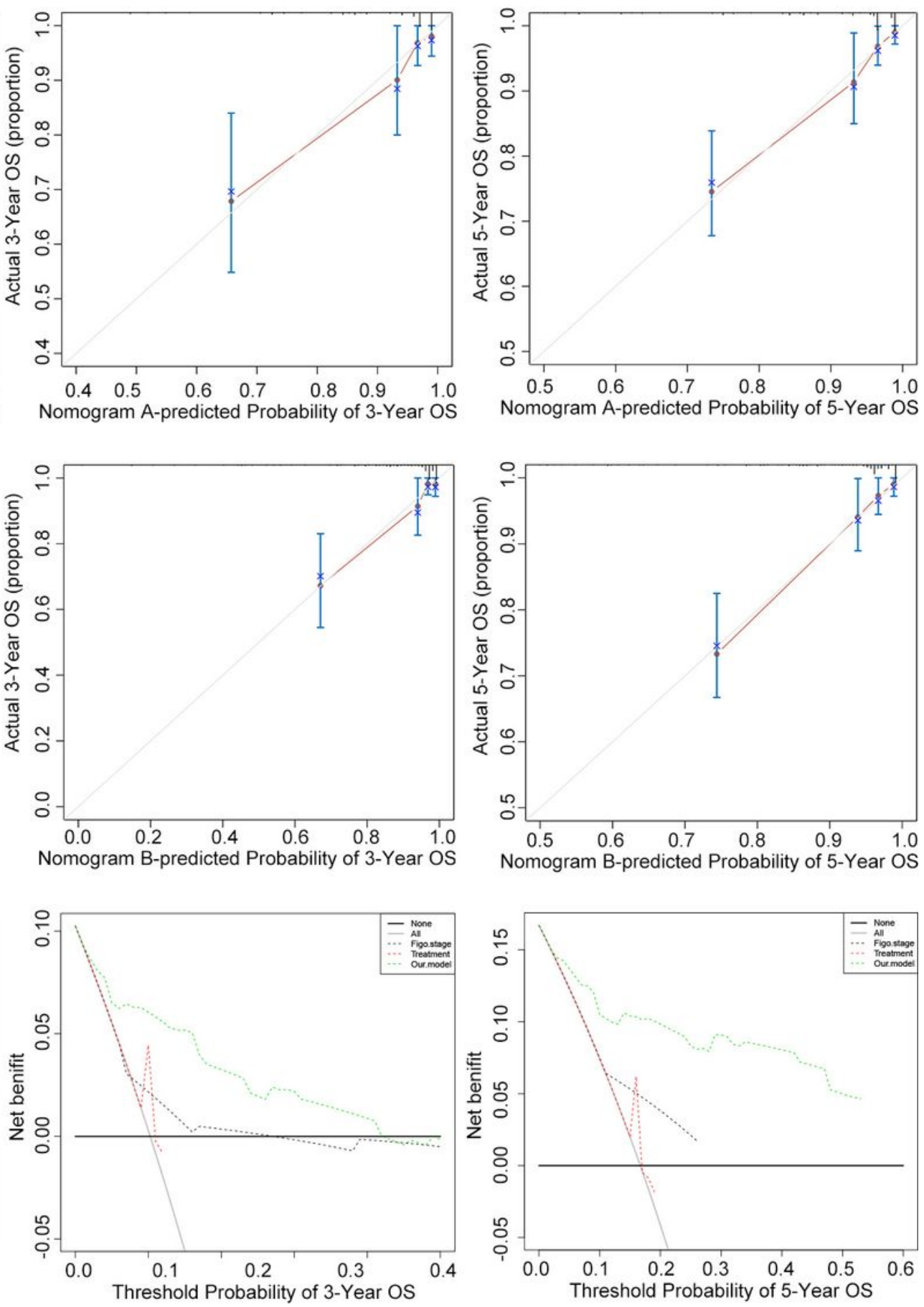

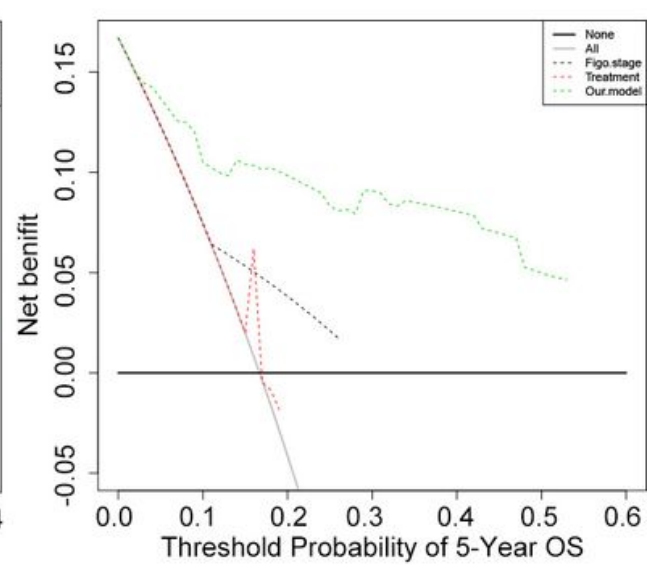

Figure 4

The calibration curves and decision curve analysis for predicting patients' overall survival (OS). The calibration curves for predicting OS at 1,3, and 5 years in all cases. (A\&B) Nomograms A and B, with the model-predicted OS plotted on the $x$-axis and actual OS plotted on the $y$-axis. Closer alignment with the diagonal line represents better estimation. (C) Decision curve analysis for 1-, 3-, and 5-year survival predictions. 

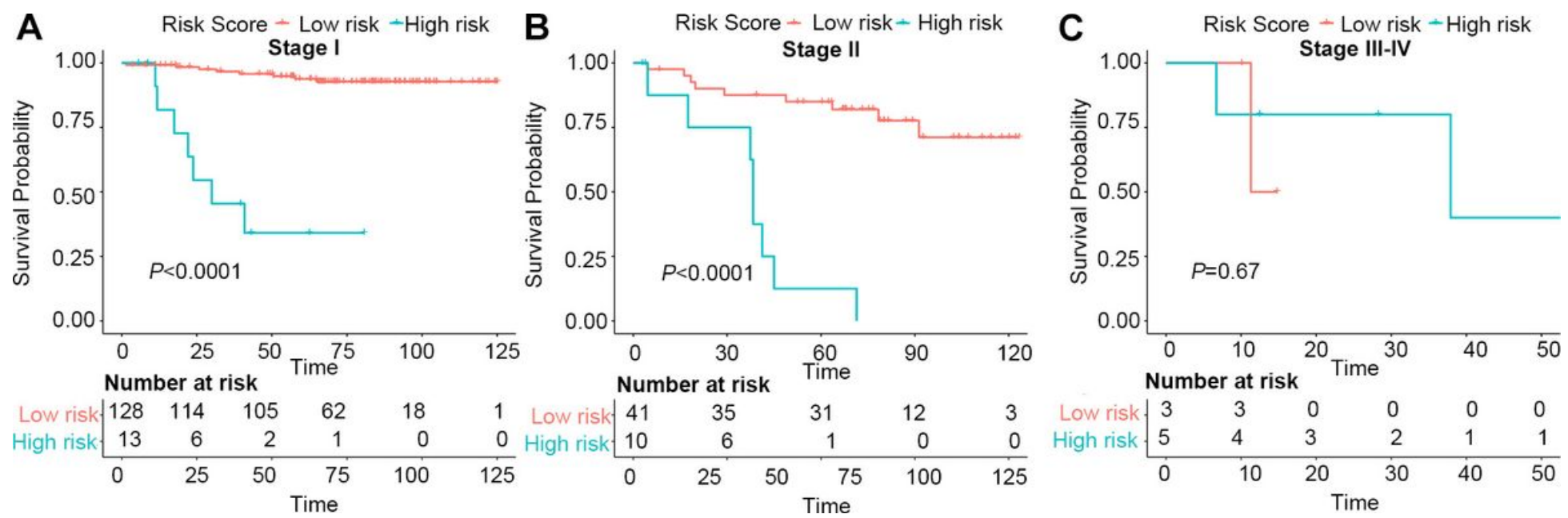

\section{Figure 5}

Graphs showing the Kaplan-Meier curves of both groups based on the predictors from the nomogram model. (A) stage I. (B) stage II. (C) stages III and IV.

\section{Supplementary Files}

This is a list of supplementary files associated with this preprint. Click to download.

- FigureS1.jpg

- FigureS2.jpg

- FigureS3.jpg

- FigureS4.jpg

- SupplementalTables.docx 